\title{
O ESTUDO DO SIGNIFICADO SOB A PERSPECTIVA DA LINGUÍSTICA/SEMÂNTICA COGNITIVA
}

Elisângela Santana dos Santos (UNEB)

\begin{abstract}
RESUMO: Este artigo tem por objetivo discorrer sobre o estudo da significação ao longo dos diferentes estágios da Semântica Lexical, destacando as suas inter-relações e dando ênfase para a investigação do significado no âmbito da Linguística Cognitiva. Para isso, apresentam-se alguns dos postulados teórico-metodológicos que norteiam a abordagem cognitivista da linguagem, destacam-se as suas principais linhas de pesquisa e tecem-se algumas considerações sobre a estreita relação entre significado, cognição, linguagem, experiências, mundo, cultura e sociedade.

PALAVRAS-CHAVE: Significado; Semântica Lexical; Linguística Cognitiva; Semântica Cognitiva.
\end{abstract}

\section{THE STUDY OF MEANING IN THE PERSPECTIVE OF COGNITIVE LANGUISTICS/SEMANTICS}

\begin{abstract}
This article aims to discuss the study of meaning throughout the different stages of Lexical Semantics, highlighting their interrelations and giving emphasis to the investigation of meaning in the context of Cognitive Linguistics. For this, we present some of the theoretical and methodological assumptions that guide the cognitive approach to language, the main lines of research and weave some considerations about the close relationship between meaning, cognition, language, experiences, world, culture and society.

KEYWORDS: Meaning; Lexical Semantics; Cognitive Linguistics; Cognitive Semantics.
\end{abstract}

\section{ALGUMAS PALAVRAS INTRODUTÓRIAS}

Os estudos sobre a significação passaram por diferentes fases ao longo dos séculos; ora sendo enfatizados, ora sendo preteridos. Algumas justificativas costumam ser dadas para isso. Se, por um lado, a falta de unidade e de uma definição precisa para significado resultaram em um certo desinteresse pelos estudos semânticos que culminaram no seu descrédito, em alguns períodos do último milênio; por outro, as múltiplas possibilidades de investigação desse mesmo objeto de estudo contribuíram para o desenvolvimento da Semântica como ciência e, por conseguinte, para o surgimento dos seus diferentes epítetos.

Ulmann (1964, p. 113), ao tentar explicar a pouca atenção dada aos estudos semânticos no passado, afirmou que "o significado é um dos termos mais ambíguos e controversos da teoria da linguagem", sendo a dificuldade de defini-lo uma das causas apontadas por Greimas (1966, p. 12-13) para justificar o comportamento receoso e, muitas vezes, refratário de alguns 
linguistas quanto às pesquisas relativas à significação. Mais recentemente, Otaola Olano (2004) defendeu que o significado ainda é uma incógnita nos estudos sobre a linguagem.

Corroborando tais afirmações, alguns linguistas brasileiros asseveraram que a falta de consenso quanto a esse tema é um dos fatores que podem ter dificultado o trabalho com a Semântica. Para Oliveira (2008, p. 13, 30), trata-se de "um nó ainda não desatado pelos linguistas”. Para Ilari e Geraldi (2006, p. 6), seus limites são imprecisos e o seu objeto não muito claro, conforme se pode ler a seguir:

[...] a semântica é um domínio de investigação de limites movediços; semanticistas de diferentes escolas utilizam conceitos e jargões sem medida comum, explorando em suas análises fenômenos cujas relações não são sempre claras: em oposição à imagem integrada que a palavra ciência evoca, a semântica aparece, em suma, não como um corpo de doutrina, mas como o terreno em que se debatem problemas cujas conexões não são sempre óbvias.

Todavia, apesar dessas observações e de outras tantas possíveis, acredita-se que a falta de consenso e de uma definição mais precisa de significado é, ao contrário do que se possa pensar, bastante proveitosa para os estudos linguísticos e para o desenvolvimento de pesquisas na área dos estudos semânticos. Verifica-se, por exemplo, que os questionamentos acerca dessa área de estudos têm dado lugar a tentativas diversas de explicação para as possíveis relações entre sentidos, significados, fatores intralinguísticos e extralinguísticos, caracterizando as múltiplas possibilidades de investigação que linguistas, semanticistas ou não, podem seguir.

Como observou Silva (2006), o interesse antigo pela mudança semântica está sendo, hoje, revalorizado pela Linguística Funcionalista e pela Linguística Cognitiva, tanto do ponto de vista sincrônico, como do ponto de vista diacrônico, o que justifica um crescente interesse em pesquisar alguns fenômenos semânticos em distintos períodos da língua portuguesa. Já Vilela (1994, p. 24) acrescenta que, diferentemente do que ocorreu no século XX, quando houve uma predominância das teorias formalistas, os estudos semânticos mais recentes têm ocupado uma posição de destaque do ponto de vista linguístico, adotando perspectivas pragmáticas, comunicativas e cognitivas, em que o léxico volta a ser objeto de interesse, assim como o uso, o indivíduo e o contexto sócio-histórico-cultural em que está inserido, conforme comprova o modelo teórico da Linguística Cognitiva.

Sendo assim, para melhor entender como o significado passou a ser analisado sob a ótica cognitivista, far-se-á, na seção seguinte, uma breve explanação sobre a análise do significado nos diferentes estágios de desenvolvimento da Semântica Lexical. 


\section{ESTUDO DO SIGNIFICADO EM ESTÁGIOS DA SEMÂNTICA LEXICAL}

A Semântica Lexical é uma ciência que estuda os fenômenos relativos à significação das palavras, isto é, dos itens lexicais ou lexemas. Um dos primeiros passos para que esse tipo de investigação tivesse maior visibilidade foi dado pelo germânico Karl Reisig que, em 1825, instituiu, nos cursos universitários que ministrava, um programa de estudo do significado, de caráter historicista, denominado Semasiologia, no qual explorou a afinidade entre a metáfora e a similaridade, assim como entre a metonímia e a contiguidade, consideradas mecanismos básicos de associação de ideias (ULLMANN, 1964, p. 16).

Todavia, ainda que essa iniciativa tenha sido importante para o desenvolvimento dos estudos semântico-lexicais, as diretrizes da nova ciência só foram traçadas um pouco mais tarde, com a publicação de um artigo assinado pelo francês Michel Bréal, datado de 1883, em uma revista de estudos clássicos, vindo a consolidar-se em 1897, quando foi registrado pela primeira vez, no livro de sua autoria, intitulado Essai de Sémantique, Science des significations ${ }^{1}$, o termo "semântica", cujo radical grego "sem" significa 'sinal, marca, significação' (CUNHA, 1986, p. 713).

Desde o seu surgimento, há mais de cem anos, a Semântica Lexical vem assumindo um rumo multifacetado que se caracteriza, sobretudo, pelos diferentes enfoques dados ao significado no decorrer dos séculos e conforme as teorias linguísticas que predominaram em cada época. Têm-se, como exemplos, a Semântica Estrutural, a Semântica Formal ou Semântica das Condições de Verdade, a Semântica Argumentativa, a Semântica da Enunciação, a Semântica das Condições de Uso, a Semântica Cognitiva, dentre várias outras.

Para efeito didático, Geeraerts (1998, p. 125) nomeou, inicialmente, os referidos estágios da seguinte maneira: Semântica Diacrônica Pré-Estruturalista ou Histórica, Semântica Estruturalista, Semântica Gerativista ou Neoestruturalista, Semântica Lógica e Semântica Cognitiva. Já em estudos posteriores (Cf. 2006, 2009), o mesmo autor propôs algumas mudanças nas denominações, a saber: o primeiro estágio passou a corresponder à Semântica Histórico-Filológica; o segundo, à Semântica Estruturalista; o terceiro, à Semântica Gerativista; o quarto, à Semântica Neoestruturalista, que se desdobra em Semântica Neo-Gerativa Formal

1 A obra consultada para a realização da presente pesquisa foi a tradução para o português, intitulada Ensaio de Semântica: ciência das significações (1992). 
ou simplesmente Neogerativista; e o quinto, à Semântica Cognitiva. Esse procedimento, conforme argumenta o próprio autor, não segue um modelo de evolução semelhante ao que se faz em Física ou Biologia, pois a sucessão de variadas perspectivas teóricas no estudo dos significados das palavras não implica, em geral, refutação nem substituição de uma teoria mais velha por uma teoria mais nova, considerada melhor. Muito pelo contrário, ao referir-se ao tema, ficam evidentes as conexões entre as distintas fases dos estudos semântico-lexicais e a relevância de trabalhos anteriores para elaboração de pesquisas e de trabalhos presentes e futuros.

O primeiro estágio, denominado de Semântica Diacrônica Pré-Estruturalista ou Histórica (GEERAERTS, 1998) ou Semântica Histórico-Filológica (GEERAERTS, 2006, p. 368374; 2009, p. 9, 19-21), predominou entre os anos de 1870 e 1930. Seus principais representantes foram Paul, Darmesteter, Nyrop, Carnoy, Stern e Bréal. Tratava-se de uma abordagem de caráter histórico-filológico, que pode ser considerada como uma das primeiras manifestações da Semântica de cunho verdadeiramente linguístico, já que se embasava na Linguística como uma disciplina empírica autônoma, diferentemente do que havia sido feito até aquela época.

Esse primeiro período que teve Bréal como o seu maior representante, conforme já mencionado, apresentou as seguintes características: a) orientação diacrônica ou histórica para análise do significado, por influência da Linguística Histórica e do método históricocomparativo, com foco não apenas no estudo da mudança semântica, mas, sobretudo, nos mecanismos propulsores desse tipo de mudança; b) concepção psicológica de significado, pois tanto os significados lexicais deveriam ser considerados entidades psicológicas e estar atrelados ao pensamento e às ideias, como as mudanças semânticas resultariam de processos psicológicos, e c) caráter hermenêutico do estudo do significado, uma vez que se defendia a possibilidade de interpretar os significados de modo subjetivo, levando em consideração as experiências e o conhecimento de mundo do sujeito interpretante.

Já a o segundo estágio, denominado Semântica Estruturalista, teve como marco inicial o trabalho monográfico de Trier, datado de 1931, e compreendeu as primeiras décadas do século XX, mais especificamente os anos de 1931 a 1963, quando predominou o Estruturalismo europeu, capitaneado por Ferdinand Saussure. Mas, outros representantes da época, como Porzig, em 1934; Goodennough, em 1956; Lounsbury, em 1956; Lyons, em 1963, e Pottier, em 1964, também se destacaram (GEERAERTS, 2009, p. 52). 
Esse estágio diferiu do anterior, exatamente em relação às suas três características. Para os seus seguidores, o estudo do significado não deveria ser atomístico, mas estar voltado para a estrutura semântica; não deveria ser diacrônico, mas sincrônico, e deveria ser autônomo, ou seja, não-psicológico. Portanto, limitava-se às relações internas ao sistema e excluía o referente (a coisa à qual o significado e o significante se referem), a história, e, principalmente, o mundo exterior e o modo como o sujeito o percebia e conceptualizava. O triângulo semiótico de Ogden e Richards (1923) ilustra bem essas questões. Eles propõem um conceito de significado que pode ser representado simbolicamente por uma forma triangular, em que se tem o pensamento ou a referência (o conceito), o símbolo (a palavra enquanto forma significante e a sua imagem acústica) e o referente (a coisa nomeada) em três extremos. Entre esses dois últimos elementos, observa-se a ausência de uma relação direta, pois se trata de uma relação atribuída, evidenciando o caráter arbitrário da linguagem.

Em outras palavras, o significado, na perspectiva Estruturalista, era determinado prioritariamente pela posição que o item lexical analisado ocupava na estrutura linguística, ou seja, as suas relações sintagmáticas e paradigmáticas, sem levar em conta os fatores extralinguísticos que as determinavam. Tal comportamento, inspirado no postulado saussureano da arbitrariedade do signo linguístico, ilustra, conforme ressaltou Salomão (1999, p. 62), o custo da precisão conquistada pelo Estruturalismo, que se caracterizava, principalmente, pelo "foco no significante” e pela “exclusão do sujeito como usuário 'voluntarioso' da linguagem” e, portanto, capaz de construir significados a partir de suas crenças, de seu modo ver e sentir a vida, da sua sócio-história.

O terceiro estágio de desenvolvimento da Semântica Lexical refere-se ao Modelo Gerativista, conforme denominado por Geeraerts $(1998 ; 2006 ; 2009)$, que vigorou entre a segunda metade da década de 60 e na maior parte dos anos 70. Numa tentativa de integrar a Semântica ao Gerativismo e relacioná-la com os estudos sintáticos priorizados por essa teoria formalista, os linguistas gerativistas Katz e Fodor (1963) mobilizaram-se em favor de uma teoria interpretativa do significado, depois desenvolvida por Katz (1972), sem grande sucesso. Embora houvesse uma tendência a dar uma maior importância aos aspectos do significado e a desviar o foco da sintaxe, essa tentativa não foi exitosa. Em defesa de uma tese que pregava a autonomia da linguagem, por considerá-la um sistema que se bastava em si mesmo, os gerativistas deram mais ênfase à sintaxe, considerando-a um módulo autônomo da gramática, em detrimento da pesquisa dos fenômenos do significado. A análise componencial proposta por esse modelo era, ao mesmo tempo, descritiva e, por influência do modelo chomskyano, altamente 
formal, sendo o sujeito, um mero usuário da língua, dotado apenas de uma competência gramatical, linguística, que lhe permitia interpretar sentenças como formas lógicas. $\mathrm{O}$ caráter mentalista dessa abordagem residia no interesse em investigar como o conhecimento linguístico do indivíduo se processava no seu cérebro, considerado uma máquina, um módulo independente das outras partes do corpo, cuja interação com o que está à volta é pouco relevante.

Como se pode perceber, o modelo proposto de Semântica Gerativa ou Interpretativa representou uma combinação das características de uma perspectiva estrutural, com o formalismo herdado da Gramática Gerativa e com a filosofia da linguagem mentalista. Isso tudo culminou no surgimento de duas novas tendências nos estudos semânticos: de um lado, tinha-se uma abordagem lógico-formal, e, de outro, uma abordagem inicialmente mentalista, que depois seguiu uma orientação psicológica, cognitiva.

Sem dúvida, o estágio referente à Semântica Gerativa alavancou importantes mudanças e tendências na história da Semântica Lexical, que ainda vigoram na atualidade. Podem ser citados, como alguns dos seus desdobramentos, além da Semântica Cognitiva, que se constituiu em um estágio à parte, a Semântica Formal e a Semântica Computacional. A Semântica Formal, também denominada Semântica Lógica busca explicar a relação entre a linguagem e o mundo, apoiando-se na lógica das condições-de-verdade e na filosofia da linguagem. É a partir dessa perspectiva, considerada também referencial, que algumas propriedades semânticas entre sentenças são explicadas em termos de verdade, a exemplo das noções de contradição, acarretamento e de ambiguidade. Quanto à Semântica Computacional, costuma-se atribuir a sua origem à Linguística Computacional, a qual tem forte ligação com a Inteligência Artificial e com as Ciências Cognitivas. Na tentativa de mostrar como o significado pode ser representado no meio digital e como a representação formal pode ser usada em processos de inferência automatizada, a Semântica/Linguística Computacional tem servido tanto como ferramenta para a linguística descritiva e teórica, como para a linguística de corpus, dirigindo-se, também, para aplicações práticas em tecnologia da linguagem, como tradução mecânica (GEERAERTS, 2009, p. 111).

Ainda de acordo com a proposta de periodização de Geeraerts (2006, 2009), o quarto estágio diz respeito à Semântica Neoestruturalista, a qual foi considerada, em Geeraerts (1998), apenas uma tendência da Semântica Gerativa tal como a Semântica Cognitiva, também se desdobra em diferentes grupos que serão apenas citados à frente, devido às suas inúmeras especificidades. Têm-se, portanto, o Modelo da Metalinguagem Semântica Natural, cujo princi- 
pal representante é Wierzbicka, e o Projeto WordNet, ao lado do paradigma de Funções Lexicais e do paradigma de Análise de Corpus Distribucional. Essas vertentes focalizam as relações lexicais e a abordagem decomposicional do significado, que encontram, também, ressonância nos modelos da Semântica Conceptual apresentados no trabalho de Jackendoff, de 1996, e na Teoria do Léxico Gerativo, de Pustejovsky, em 1994, que, embora se enquadrem na abordagem Neostruturalista, assemelham-se ao paradigma da Gramática Gerativa, o que justifica as denominações atribuídas por Geeraerts (2006, p. 398-415; 2009, p. 116-165) a esses desdobramentos de Semântica Neo-Gerativa Formal ou simplesmente Semântica Neogerativista.

Por fim, encontra-se o quinto estágio da Semântica Lexical, a Semântica Cognitiva, que surgiu entre fins dos anos 70 e início da década de 80, em meio a discordâncias de alguns gerativistas, que, influenciados pelas ciências cognitivas e pelos avanços da Inteligência Artificial e da modelagem computacional e inconformados com a pouca atenção dada ao significado linguístico de fato, demonstraram uma forte reação à teoria chomskiana. Seus principais representantes, Johnson, Talmy, Langacker e Lakoff, não só questionaram a separação entre a Sintaxe, a Semântica e a Pragmática, como se opuseram à exclusão do uso linguístico, passando a tratar os fenômenos semântico-lexicais sob a ótica de uma nova proposta teórica: a Linguística Cognitiva. Vale lembrar que Lakoff tornou-se uma das figuras mais importantes desse novo modelo teórico, não só por protagonizar uma longa história de luta entre a Semântica Gerativa e a Gramática Gerativa de Chomsky, como também por defender o Experiencialismo, bem como propor uma versão ampliada da Teoria do Protótipo, um pouco diferente dos moldes pautados na Psicolinguística de Eleanor Rosch, na década de 70, e por desenvolver a Teoria da Metáfora Conceptual, que considera a metáfora, assim como a metonímia, mecanismos conceptuais por excelência e não meros ornamentos linguísticos presentes apenas nos textos literários.

Em face disso, costuma-se considerar, como marco inaugural para os estudos semânticos desenvolvidos sob a égide cognitivista, o livro Methaphors we live by, de autoria de George Lakoff, em parceria com Mark Johnson, publicado em 1980, em inglês, e traduzido para o português, com o título Metáforas da vida cotidiana, em 2002. No entanto, linguistas como Cuenca e Hilferty (1999, p. 11) afirmam que só no ano de 1987 nasceu, de fato, essa ciência, devido à publicação do primeiro volume de Foundations of cognitive grammar, de Langacker, e do livro Women, fire and dangerous things, de Lakoff, obra que, segundo Batoréo (2000, p. 131), é referência para outros trabalhos produzidos nessa área. Silva $(2004$, p. 1), porém, con- 
sidera que os pontos de partida para institucionalizar e consolidar a Linguística Cognitiva como paradigma científico foram a criação da International Cognitive Linguistics Association e a realização do primeiro International Cognitive Linguistics Conference, ocorridos em Duisburg, na Alemanha, em 1989, seguidos da fundação da revista Cognitive Linguistics e da coleção Cognitive Linguistics Research, em 1990.

Inicialmente, os principais representantes desse novo modelo não chegaram a organizar um programa em conjunto ou uma escola linguística, mas se uniram por uma série de ideais e de convicções, apoiando-se em uma filosofia de base. Também, não havia características de uma teoria pré-estabelecida, como aconteceu com o Estruturalismo e com o Gerativismo. Daí ora ser empregada indistintamente a designação Linguística Cognitiva, ora Semântica Cognitiva, ora Gramática Cognitiva (BATORÉO, 2000, p. 131).

Geeraerts (2006, p. 2) descreve a Linguística Cognitiva como um arquipélago ao invés de uma ilha, ao contrário de outras teorias, já que esse modelo teórico não possui um único fundador nem uma área de estudo claramente delimitada. Trata-se de um conglomerado de centros de investigação espalhados pelos EUA, pela Europa e, mais recentemente, pela Ásia e pela América do Sul que partilham de uma perspectiva geral comum e desenvolvem distintos programas e teorias linguísticas (ainda) não redutíveis a uma única e uniforme teoria da linguagem, conforme ressalta Silva (2007, p. 52).

Como foi possível verificar, as diferentes fases da Semântica Lexical, até aqui citadas, apresentam pontos de intersecção e de discordância perceptíveis em todos os estágios de desenvolvimento destacados. Tais inter-relações também podem ser visualizadas, na figura a seguir, adaptada de Geeraerts (2006, p. 407): 
Figura — Principais estágios da Semântica Lexical e suas inter-relações

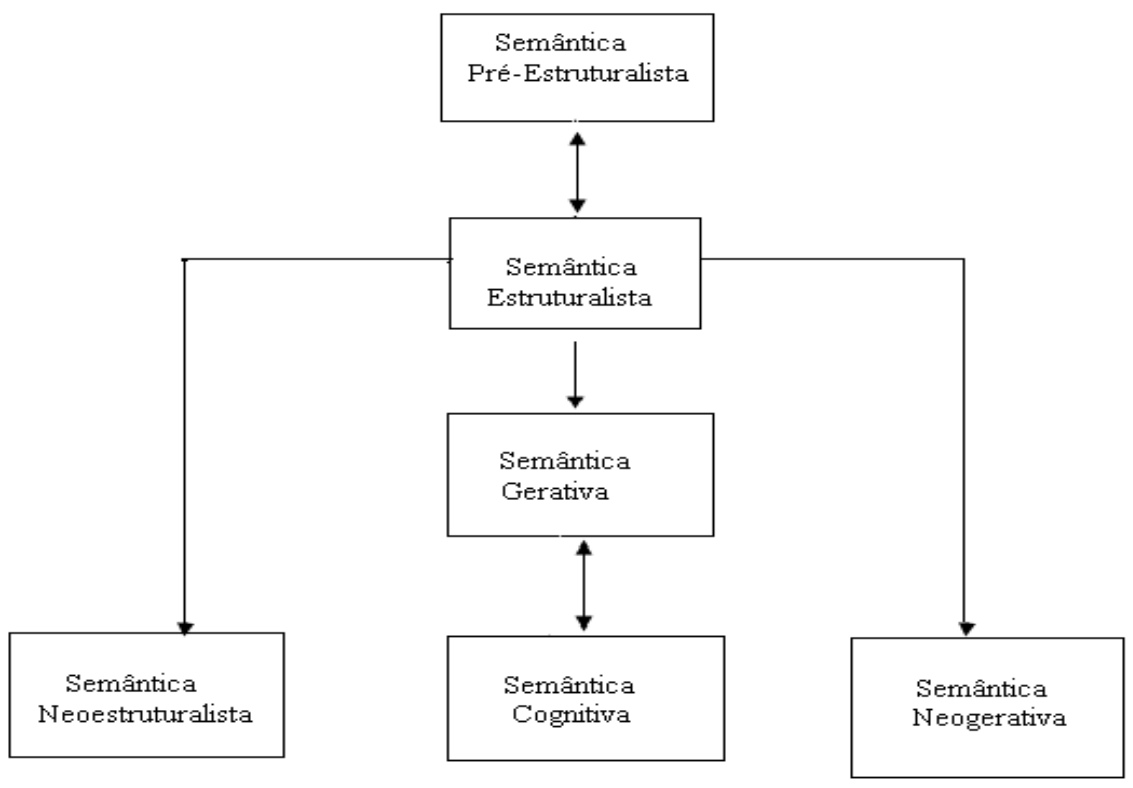

Fonte: Geeraerts (2006, p. 407)

Nesse diagrama, o autor mostra que a Semântica Cognitiva compartilha com a Semântica Histórico-Filológica ou Pré-Estruturalista as concepções psicológica e enciclopédica de significado e com a Semântica Gerativa a concepção mentalista, ao mesmo tempo em que a abordagem Estruturalista herda algumas características da Pré-Estruturalista e assemelha-se também à Gerativa, por defender a autonomia da estrutura semântica, preocupando-se com as relações sintagmáticas e paradigmáticas, tal como fazem as Semânticas Lógicas Neoestruturalista e Neogerativa, visto que buscam uma abordagem da língua imanente, autonomista e presa ao rigor formal.

Para melhor conhecer o modelo teórico denominado Linguística Cognitiva e como se dá o estudo do significado segundo o seu enfoque, serão mostrados, nas seções seguintes, alguns princípios que o norteiam, bem como as suas diferentes, mas nem por isso desconectadas, linhas de investigação. 


\section{FUNDAMENTOS DA LINGUÍSTICA COGNITIVA PARA O ESTUDO DO SIGNIFICADO E SUAS PRINCIPAIS LINHAS DE INVESTIGAÇÃO}

O modelo teórico cognitivista para o estudo do significado e seus desdobramentos se constitui, hoje, como importante paradigma científico, que apresenta princípios, métodos e variadas linhas de investigação, com vistas a explicar a construção do significado e a estudar os diferentes fenômenos semânticos.

Apoiando-se em Rudzka-Ostyn (1993, p. 1-2), Silva (1999, p. 11) considera que as concepções gerais e comuns da linguagem e do conhecimento/cognição podem ser assim resumidas: 1) a linguagem está intimamente ligada a outros domínios cognitivos, daí haver a necessidade de uma investigação interdisciplinar; 2) a estrutura linguística depende da conceptualização e está condicionada à experiência individual, à experiência do mundo exterior e à relação do indivíduo com esse mundo; 3) as unidades linguísticas estão sujeitas à categorização, a qual origina estruturas com base em protótipos e são tipicamente polissêmicas; 4) a gramática é motivada por aspectos semânticos; 5) a significação de uma unidade linguística é uma estrutura conceptual convencionalmente associada a essa unidade e, por fim, 6) as teses sobre a autonomia da linguagem e as dicotomias difundidas por outras teorias linguísticas devem ser rejeitadas.

Cuenca e Hilferty (1999, p. 18-19), por sua vez, defendem que a base para a definição da teoria cognitiva consiste nos postulados a seguir: 1) o estudo da linguagem não pode se separar de sua função cognitiva e comunicativa, devendo-se basear no uso; 2) a categorização ou operação mental realiza-se a partir de estruturas conceptuais, de relações prototípicas e por semelhanças de família, com limites difusos entre as categorias, e não a partir de condições necessárias e suficientes; 3) a função primeira da linguagem é significar, devido ao seu caráter simbólico; portanto, não se pode separar o componente gramatical do componente semântico; 4) a gramática consiste na estruturação e simbolização do conteúdo semântico a partir de uma forma fonológica, desse modo, o significado é um conceito fundamental na análise gramatical, e 5) a gramática é uma entidade em evolução contínua, isto é "um conjunto de rotinas cognitivas que se constituem, se mantém e se modificam pelo uso" (LANGACKER, 1987, p. 57).

Já Batoréo (2000, p. 165), complementando o que disseram os referidos autores, apresenta como bases metodológicas desse modelo teórico, os seguintes pressupostos: a) o signifi- 
cado reduz-se à conceptualização, que deve ser entendida como experiência mental e explicitada como processamento cognitivo; b) a gramática é um inventário estruturado de unidades linguísticas convencionais, sujeitas à categorização, estruturada com base em esquemas e protótipos; c) uma expressão linguística, utilizada com frequência, pode dar origem à polissemia; d) as estruturas semânticas caracterizam-se em função de domínios cognitivos, devidamente configurados e sujeitos a extensões e elaborações, e e) as estruturas semânticas são portadoras de imaginários convencionalizados, que permitem formar constructos conceptuais.

Como se pode notar, diante dos princípios e fundamentos apresentados, a Linguística Cognitiva busca não só descrever os fenômenos linguísticos que se manifestam na linguagem humana, como também tenta explicar o que subjaz à sua manifestação, levando em conta fatores subjetivos, emocionais, mas sobretudo, sociais e culturais que interferem na formulação do pensamento e na elaboração da linguagem. Além disso, busca analisar, dentre outras coisas, de que maneira se estabelece a interdependência linguagem/mente e como o subjetivismo do homem e o seu conhecimento enciclopédico interferem na formulação de conceitos.

Os inúmeros encontros, simpósios, conferências e congressos realizados em diferentes continentes, no âmbito dos estudos cognitivistas, ao longo dos últimos anos, evidenciam um processo rápido de amadurecimento e de crescimento desse modelo teórico, confirmado pelo volume de publicações disponíveis e pelos grupos de pesquisa organizados e representativos de que se têm notícias. Conta-se, atualmente, com um número considerável de pesquisadores nessa área, dentro e fora do Brasil, e com um importante acervo de obras bibliográficas e eletrônicas.

As principais linhas de investigação da Linguística Cognitiva apontadas por Silva (2004, p. 1722; 2007, p. 53) podem ser assim enumeradas² ${ }^{2}$ I) a Semântica Cognitiva, que estuda, em linhas gerais, o significado como conceptualização e tem como representantes Lakoff, Langacker e Talmy; II) a Gramática Cognitiva, que investiga as construções como objeto primário de descrição e o conhecimento gramatical, que está representado na mente dos falantes, cujos modelos mais elaborados são a Gramática Cognitiva, de Langacker, e a Gramática das Construções, de Goldberg e de Croft; III) a Teoria do Protótipo, que se dedica a estudar a categorização linguística, a polissemia, a mudança semântica, a variação léxica, a análise das categorias em forma de redes radiais e redes esquemáticas, que tem por representantes Taylor,

2 Para maiores informações, consultar o artigo intitulado Os estudos de Linguística Cognitiva do português de Silva (2007, p. 53). 
Geeraerts, Lakoff e Langacker; IV) a Teoria da Metáfora Conceptual, que apresenta estudos sobre metáfora e metonímia conceptuais, tanto no nível do léxico, como nos da gramática e do discurso, e também se dedica a estudar os esquemas de imagens ou padrões de movimento no espaço, a manipulação de objetos e interações perceptivas, cujos expoentes são Lakoff e Johnson, dentre outros; V) a Teoria dos Marcos/Quadros Conceptuais ou Frame Semantics, com Filmore e sua implementação no projeto Framenet; VI) a Teoria dos Espaços Mentais, com Fauconnier; VII) a Teoria da Integração Conceptual, com Fauconnier e Turner; VIII) a Teoria dos Modelos Culturais e o desenvolvimento da Linguística Cultural, com Palmer, Lakoff e Tomasello e Kövecses; IX) a Teoria da Gramaticalização, com Hopper e Trougott, Trougott e Dasher; X) a Teoria da Subjetivação, com Langacker, e desenvolvida mais recentemente por Athanasiadou, Canakis e Cornillie; e XII) a Teoria Neural da Linguagem, com Lakoff.

Na Europa e, mais especificamente, em Portugal, os estudos em Linguística Cognitiva enquadram-se nos domínios da Semântica Cognitiva, da Gramática Cognitiva, da Gramaticalização e Discurso e de estudos interdisciplinares, destacando-se vários nomes, distribuídos em diferentes centros de pesquisa, a exemplo de: Isabel Hub Faria, José Pinto de Lima e Clotilde Almeida, na Faculdade de Letras de Lisboa, e Hanna Batoréo, na Universidade Aberta, em Lisboa; Mário Vilela, na Faculdade de Letras do Porto; Ana Macário Lopes, na Faculdade de Letras de Coimbra; Rosa Lídia Coimbra, na Universidade de Aveiro; José de Sousa Teixeira, na Universidade do Minho, e Augusto Soares da Silva, na Faculdade de Filosofia da Universidade Católica Portuguesa, no Centro Regional de Braga, onde foi implantado o primeiro Curso de Mestrado em Linguística Portuguesa - Perspectiva Cognitiva, em 1998, e onde foi, também, criado o Mestrado em Ciências Cognitivas, que inter-relaciona as áreas da Filosofia da Mente, da Linguística Cognitiva e das Neurociências.

No Brasil, centros de pesquisa, de norte a sul do país, que integram, na sua grande maioria, o Grupo de Trabalho Linguística e Cognição da ANPOLL, vêm desenvolvendo diferentes linhas de estudo nessa área e já se fazem presentes em vários programas de pós-graduação do país, tendo como principais expoentes: Maria Margarida Salomão (pioneira nos estudos de Linguística Cognitiva no Brasil), Neusa Salim Miranda e Maria Cristina Name, na Universidade Federal de Juiz de Fora; Lilian Ferrari e Maria Lúcia Leitão de Almeida, na Universidade do Rio de Janeiro; Heliana Melo, na Universidade Federal de Minas Gerais; Ana Cristina Pelosi Silva de Macedo e Emília Maria Peixoto Farias, na Universidade Federal do Ceará; Ataliba T. de Castilho, na Universidade Federal de São Paulo; Edwiges Morato e Ingedore Villaça Koch, na Universidade Estadual de Campinas; Margarida Basílio e Helena Martins, na 
Pontifícia Universidade Católica do Rio de Janeiro; Heronides Moura, na Universidade Federal de Santa Catarina, e Heloísa de Moraes Feltes, na Universidade de Caxias do Sul; Aurelina Ariadne Domingues Almeida, na Universidade Federal da Bahia.

\section{O SIGNIFICADO SOB O OLHAR DA LINGUÍSTICA/SEMÂNTICA COGNITIVA}

Ao contrário do que se podia observar num passado ainda recente, o estudo do significado passou a ocupar um lugar de destaque para a Linguística Cognitiva, transpondo inúmeras barreiras nos últimos tempos e reafirmando, assim como prenunciou Bréal no século XIX, que os múltiplos sentidos atribuídos a coisas, situações, fatos, palavras resultam das experiências, dos movimentos corpóreos, da interação dos seres humanos com o mundo que os cerca, e não apenas de um processamento mental, como acreditaram os teóricos adeptos da teorias linguísticas de cunho formalista que surgiram no século XX.

Ao posicionar-se a esse respeito, Silva (2004, p. 2) compartilha com Langacker (1999, 2007, p. 422) a ideia de que a linguagem deve ser vista como parte integrante da cognição e não como um módulo isolado, devendo, por isso, ser estudada em seu uso e no contexto da conceptualização, como se pode constatar na citação a seguir:

[...] as mentes individuais não são entidades autônomas, mas corporizadasencarnadas e altamente interactivas com o seu meio; e é através dessa interação e acomodação mútua que a cognição e a linguagem surgem, se desenvolvem e se estruturam. Não existe, pois, propriamente linguagem humana independentemente do contexto sócio-cultural. Mas não é menos verdade que a linguagem reside primeiramente nas mentes individuais, sem as quais a interacção não poderia ocorrer (SILVA, 2004, p. 2).

Oliveira (2006, p. 43) reforça essa ideia, ao salientar que o significado está no corpo que vive, que se move, que está em várias relações com o meio e não na correspondência entre palavras e coisas simplesmente. Essa concepção é também defendida por Martelotta e Palomanes (2009, p. 183), quando afirmam que a conceptualização está fortemente ligada à cognição e, por conseguinte, à experiência corpórea, social, cultural e histórica do indivíduo:

Toda informação é posicionada, no sentido de que, normalmente, não falamos a respeito do que o mundo é, mas da visão que temos dele. Ou seja, os conceitos humanos associam-se à época, à cultura e até mesmo a inclinações individuais caracterizadas no uso da linguagem. Incorpora-se, portanto, no processo de significação o sujeito, ou seja, a perspectiva de quem produz no discurso [...]. 
Nessa afirmação, duas questões importantes da Linguística/Semântica Cognitiva se evidenciam: a subjetividade na formulação de conceitos e o caráter perspectivista do significado. Ambos caracterizam a orientação interpretativa e, portanto, hermenêutica dessa ciência. Sendo assim, os significados resultam de uma representação mental particular, subjetiva, que decorre de processos cognitivos (como atenção, percepção, memória, categorização etc.) do indivíduo, que, por sua vez, estão atrelados a aspectos culturais, sociais, políticos, entre outros.

Para explicar como tudo isso é processado no cérebro humano, a Linguística Cognitiva utiliza a noção de conceptualização. Segundo Langacker (2007, p. 431), a conceptualização consiste no ato de envolver-se no mundo e inclui a experiência perceptual, o controle central da atividade motora e as sensações cinestésicas que ela induz, daí a natureza enciclopédica do significado linguístico. Por isso, uma análise semântica conceptualista, de base experiencial, não pode estar dissociada do uso, que, por sua vez, reflete os mecanismos de abstração provenientes de esquemas imagético-cinestésicos, a exemplo da metáfora e da metonímia, e da categorização, que são responsáveis pela formulação dos conceitos. Essa abordagem está claramente expressa no experiencialismo ou realismo corporizado (embodied realism) defendido por Lakoff e Johnson (LAKOFF, 1987; JOHNSON, 1987; LAKOFF \& JOHNSON, 1999).

Assim, diferentemente dos modelos de análise sêmica ou componencial, em que o léxico é concebido como uma organização estrutural e o significado pode ser analisado por meio da identificação de semas, isto é, de traços distintivos mínimos, o estudo da significação, segundo o enfoque cognitivo, pauta-se na experiência humana e, portanto, na relação que os seres humanos estabelecem com o meio, com o mundo. Para Lakoff (1987), experiência envolve a totalidade da experiência humana e tudo o que nela desempenha um papel, assim incluem-se a natureza de nossos corpos, capacidades geneticamente herdadas ou formas de fisicamente operar no mundo, nossa organização social, cultural etc.

Em síntese e corroborando algumas palavras de Geeraerts (2006, p. 4-5), pode-se dizer que o significado linguístico, segundo o enfoque cognitivo, é perspectivista, porque não reflete apenas a realidade objetiva do mundo; é dinâmico e flexível, porque está suscetível a mudanças e transformações históricas, culturais, dentre outras; é enciclopédico e não-autônomo, pois reflete o conhecimento e as experiências de quem o constrói, não podendo ser considerado algo isolado da mente e independente de outras capacidades cognitivas, e, por fim, reiterando tudo que já foi mencionado, o significado linguístico é baseado no uso da língua e na experiência individual e coletiva dos indivíduos que a utilizam. 
Dentre os vários fenômenos semânticos que podem ser estudados sob a ótica da Linguística Cognitiva, um, em especial, destaca-se pela sua complexidade e pelo seu caráter polêmico e inconcluso. Trata-se da polissemia, objeto de estudo do trabalho desenvolvido por Santos (2011), na sua tese de doutoramento. Mas, esse é o tema de um outro artigo.

\section{ALGUMAS PALAVRAS PARA CONCLUIR}

Como se pode verificar, por meio dessa breve explanação, os estudos acerca da significação sob a abordagem cognitivista trouxe, nas três últimas décadas, contribuições importantes para o conhecimento de algumas capacidades e mecanismos cognitivos envolvidos no processo de construção dos sentidos e no uso da linguagem como manifestação do pensamento. De fato, os limites do significado são imprecisos, mas nem por isso o seu caráter deve ser interpretado como obscuro ou controvertido; sua análise está para além da mera observação de um contexto linguístico, tornando a sua investigação ainda mais instigante.

Em face das questões apresentadas, resta considerar, de modo bastante sintético e previsível, que significar, de acordo com a Semântica Cognitiva, é essencialmente conceptualizar, o que implica dizer que se trata de um processo que envolve aspectos sócio-histórico-culturais, experienciais, sendo, portanto, dinâmico, flexível, subjetivo, hermenêutico.

Por último para concluir o texto, mas não a discussão, retomam-se algumas palavras de Silva (2010, p. 52): "Finalmente, a Semântica Cognitiva oferece hoje um contributo da maior importância para o desenvolvimento da semântica lexical e da lexicologia, justamente porque representa uma forma recontextualizante e maximalista de fazer semântica”.

\section{REFERÊNCIAS}

BATORÉO, Hanna Jakubowicz. Expressão do espaço no português europeu. Contributo psicolingüistico para o estudo da linguagem e cognição. Lisboa: Fundação Caloust Gulbeikian/Fundação para a Ciência e a Tecnologia, 2000.

BRÉAL, Michel. Ensaio de Semântica: ciência das significações. Trad. Aída Ferras et al. São Paulo: EDUC \& Pontes, 1992.

CUENCA, Maria Josep; HILFERTY, Joseph. Introducción a la Linguística Cognitiva. Barcelona: Ariel, 1999. 
CUNHA, Antônio Geraldo da. Dicionário etimológico Nova Fronteira da língua portuguesa. 2 ed. rev. acresc. Rio de Janeiro: Nova Fronteira,1986.

GEERAERTS, Dirk. Hundred years of lexical semantics. In: VILELA, Mário; SILVA, Fátima (Org.). Actas do $1^{\circ}$ Encontro Internacional de Linguística Cognitiva. Porto, 1998.

GEERAERTS, Dirk. Prototype theory. In: GEERAERTS, Dirk (ed). Cognitive Linguistics: Basic Readings. Berlim/New York: Mouton de Gruyter, 2006.

GEERAERTS, Dirk. Theories of Lexical Semantics. New York: Oxford University Press, 2009.

GREIMAS, A. J. Semântica estrutural: pesquisa de método. 2. ed.Trad. Haquira Osakabe; Izidoro Blikstein. São Paulo: Cultrix, 1966.

ILARI, Rodolfo; GERALDI, João Wanderley. Semântica. 11. ed. São Paulo: Ática, 2006. (Princípios; 8).

JOHNSON, Mark. The body in the mind: the bodily basis of meaning. Imagination, and reason. Chicago: The University of Chicago Press, 1987.

KATZ, Jerold J.; FODOR, Jerry A.. The structure of a semantic theory. Language, 39, 1963.

KATZ, Jerold J. Semantic Theory. New York: Harper and Row, 1972.

LAKOFF, George; JOHNSON, Mark. Metaphors we live by. Chicago: The University of Chicago Press, 1980.

LAKOFF, George. Women, fire, and dangerous things: what categories reveal about the mind: Chicago and London: The University of Chicago Press, 1987.

LAKOFF, George; JOHNSON, Mark. Philosophy in the flesh: the emboided mind and its challenge to western tought. New York: Basic Books, 1999.

LAKOFF, George; JOHNSON, Mark. Metáforas da vida cotidiana. Trad. Maria Sophia Zanotto, Campinas, S.P. : Mercado de Letras; São Paulo: EDUC, 2002. (Coleção As Faces da Lingüística Aplicada).

LANGACKER, R. W. Foundations of Cognitive Grammar. Vol. 1: Theoretical Prerequisites. Stanford: Stanford Press, 1987.

LANGACKER, R. W. Foundations of Cognitive Grammar.Vol. 2: Descriptive Application. Stanford: Stanford Press, 1991.

LANGACKER, R. W. Gramar e conceptualization. Berlim, New York: Mouton de Gruyter, 1999.

LANGACKER, R. W. In: GEERAERTS, Dirk; CUYCKENS, Hubert. The Oxford Handbook of Cognitive Linguistics. Oxford/New York: Oxford University Press, 2007.

MARQUES, Ma Helena Duarte. Iniciação à semântica. 5 ed. Rio de Janeiro: Jorge Zahar, 2001. 
MARTELOTTA, Mário Eduardo; PALOMANES, Roza. Linguística Cognitiva. In: MARTELOTTA et al. (Org.). Manual de lingüistica. São Paulo: Contexto, 2009.

OTAOLA OLANO, Concepción. Lexicología y semántica léxica. Madrid: Ediciones Académicas, S.A., 2004.

OGDEN, C. K.; RICHARDS, I. A.. The meaning of meaning: a study of the influence of language upon thought and of science of symbolism. Flórida: Harcourt Brace Jovanovich, 1923.

OLIVEIRA, Roberta. Semântica. In: MUSSALIM, Fernanda; BENTES, Anna Christina (Org.). Introdução à lingüístia: domínios e fronteiras, v.2. 5.ed. São Paulo: Cortez, 2006.

RUDZKA-OSTYN, Brygida. Introduction. In: GEIGER \& RUDZKA-OSTYN. Conceptualizations and Mental Processing in Language, 1993.

SALOMÃO, Maria Margarida Martins. A questão da construção do sentido e a revisão da agenda dos estudos da linguagem. In: Veredas: Revista de Estudos lingüísticos on line. v.4, n.1, 1999. Disponível em: http:www.revistaveredas.ufjf.br. Acessoo em: jul. 2009.

SANTOS, Elisângela Santana dos. Salvador: A polissemia do verbo tomar ao longo da história da língua portuguesa: um estudo à luz da Linguística Cognitiva. UFBA, 2011.

SILVA, Augusto Soares da. A semântica do deixar: uma contribuição para a abordagem cognitiva em semântica lexical. Lisboa: Fundação Calouste Gulbenkian e Fundação para a Ciência e Tecnologia, 1999.

SILVA, Augusto Soares da. Linguagem, cultura e cognição, ou a lingüística cognitiva. In: SILVA, Augusto Soares da.; TORRES, Amadeu; GOLÇALVES, Miguel (Org.). Linguagem, cultura e cognição: Estudos de Lingüística Cognitiva. v. 4. Coimbra: Almedina, 2004.

SILVA, Augusto Soares da. O mundo dos sentidos em português: polissemia, semântica e cognição. Coimbra: Almedina, 2006.

SILVA, Augusto Soares. Os estudos de Linguística Cognitiva do Português. Revista Portuguesa de Humanidades. Estudos Linguísticos, 11-1, 2007.

SILVA, Augusto Soares. Palavras, significados e conceitos: o significado lexical na mente, na cultura e na sociedade. Cadernos de Letras da UFF — Dossiê: Letras e cognição, $\mathrm{n}^{\circ}$ 41, p. $27-$ $53,2010$.

TALMY, Leonard. How language structures space. In: H. Pick e L. Acredolo (Eds.) Spatial Orientation: Teory, Research, and Application. New York: Plenum Press, 1983.

TAMBA-MECZ, Iréne. A semântica. Trad. De Marcos Marcionilo. São Paulo: Parábola, 2006.

ULMANN, Stephen. Semântica: uma introdução à ciência do significado. Trad. J. A. Osório Mateus. 5.ed. Lisboa: Fundação Calouste Gulbenkian, 1964.

VILELA, Mário. Estudos de lexicologia do português. Coimbra: Almedina, 1994.

Recebido em 15 de março de 2015.

Aceito em 13 de junho de 2015. 
